\title{
Rural America Depends on the Food Stamp Program to Make Ends Meet
}

$A_{\text {people and landscape-from large metropolitan }}^{\text {merica's strength flows from the diversity of its }}$ regions to small cities and rural communities. Some of these areas are thriving while others experience serious economic problems. Many rural areas, in particular, face challenges related to changing economic structure, globalization, and out-migration. In these communities, the federal Food Stamp Program plays a vital role. With only a small outlay from states for administrative costs, it benefits the most vulnerable and needy populations, including significant numbers of rural children, disabled and elderly persons, and low-income working families.

Rural Americans disproportionately rely on the Food Stamp Program to help purchase food for a healthy diet. Based on our analysis of data from the Survey of Income and Program Participation (SIPP), 22 percent of the nation's population lived in nonmetropolitan or "rural" areas in 2001, but a full 31 percent of food stamp beneficiaries lived there. Overall, 7.5 percent of the nation's rural population relied on food stamps, compared with 4.8 percent of urban residents. ${ }^{1,2}$

With 4.6 million rural residents relying on the Food Stamp Program as of 2001, budget cuts being consid-

1 Here, "rural" refers to counties that were nonmetropolitan in 2001 (the year for which we analyze data from the Survey of Income and Program Participation). New definitions were released in 2003, but in 2001, nonmetro counties had neither (a) a city of at least 50,000 residents or (b) an urbanized area of 50,000 or more and total area population of at least 100,000 . In addition, they were not economically tied to counties that did have one or both of these characteristics. See "Measuring Rurality: New Definitions in 2003," http://www.ers.usda.gov/Briefing/Rurality/ Newdefinitions/. "Urban" refers to counties that were metropolitan in 2001, by virtue of meeting one or more of the criteria listed above. Metropolitan counties include both central cities and surrounding suburbs.

2 All 2001 numbers in this report rely on 2001 Survey of Income and Program Participation (SIPP), Wave 1 data analyzed by the authors, unless otherwise noted. The SIPP is a nationally representative survey of American ered in Congress are particularly troubling for rural areas. As part of this year's federal budget agreement, the Senate and House Agriculture Committees must cut $\$ 3$ billion over five years in programs under their jurisdiction, which includes food stamps, agricultural subsidies, and conservation programs. These cuts could result in reduced food stamp benefits and limited eligibility for millions of rural children, disabled adults, and families living in poverty. Since benefits go overwhelmingly to households that are eligible, few if any savings can be achieved by eliminating fraud. ${ }^{3}$ Thus, any significant reductions will inevitably force the government to reduce benefits and tighten eligibility requirements.

Food Stamp Recipients in Rural and Urban America, 2001

\begin{tabular}{lcc}
\hline & RURAL & URBAN \\
\hline Total population (in millions) & 61.6 & 217.6 \\
\hline Received food stamps (in millions) & 4.6 & 10.4 \\
\hline Percent receiving food stamps & 7.5 & 4.8 \\
\hline
\end{tabular}

Source: 2001 SIPP, Wave 1 Core Data

households. One purpose of the SIPP is to collect detailed data on income, labor force activity, government program participation, and demographic characteristics to measure the effectiveness of existing federal, state, and local programs. It was used here because it allows analysis of individualin addition to household—characteristics. Several studies have shown an underreporting of Food Stamp participation in the SIPP, so the numbers and rates in this policy brief may actually understate the program's value to rural communities. For example, administrative data from Food and Nutrition Service has FS participation at 17 million in 2001. For more information on the SIPP, see http://www.sipp.census.gov/sipp/.

3 Rosenbaum, Dorothy. 2005. "The Food Stamp Program is Effective and Efficient: Savings Cannot be Achieved by Targeting 'Waste, Fraud, and Abuse." Center on Budget and Policy Priorities. Washington, DC. 


\section{Poverty and the Food Stamp Program in Rural America}

The Food Stamp Program, which was established as a pilot project in the early 1960s and was expanded nationwide in the early 1970s, helps low-income families and individuals purchase a nutritionally adequate diet and reduces hunger in America. While the Food Stamp Program makes a large difference in people's lives, the benefits remain modest. The average food stamp benefit equals $\$ 1$ dollar per person per meal. ${ }^{4}$ The typical food stamp household received a monthly benefit of $\$ 185$ and had a gross monthly income of $\$ 640 . .^{5}$

Since the federal government began reporting statistics on poverty in the 1960s, the proportion of rural residents with incomes below the poverty level has been consistently higher than that of urban residents. In 2001, the rural poverty rate was 14.2 percent, more than three percentage points higher than the urban poverty rate. ${ }^{6}$ Given that the Food Stamp Program serves the neediest and most vulnerable people in our nation, it is not surprising that a disproportionate share of rural residents participate in the program.

In 2001, 7.5 percent of all rural residents participated in the Food Stamp Program, while 4.8 percent of urban residents participated. ${ }^{7}$ Clearly, some of the difference between participation rates in rural and urban areas can be attributed to higher poverty levels but other factors may be at work as well. Research shows that people who are eligible for the program participate at higher rates in rural areas. A 1998 study found that 73 percent of people who were eligible for food stamps in rural areas participated in the program, compared

4 Rosenbaum, Dorothy and Zoe Neuberger. 2005. "Food and Nutrition Programs: Reducing Hunger and Bolstering Nutrition." Center on Budget and Policy Priorities, Washington, D.C.

5 Food and Nutrition Service, U.S. Department of Agriculture. "Characteristics of Food Stamp Households: Fiscal Year 2003," http://www.fns.usda. gov/oane/MENU/Published/FSP/FILES/Participation/2003Characteristics. htm.

6 U.S. Census Bureau, Historical Poverty Tables, http://www.census.gov/ hhes/poverty/histpov/hstpov8.html.

7 In this report, the participation rate is defined as the number of food stamp participants as a share of total population. USDA defines participation rate as the number of participants as a share of the population eligible for benefits. with only 63 percent in urban areas. The researchers concluded that higher participation rates were related to household size (rural households receiving food stamps tended to have larger numbers of children) and smaller, more user-friendly offices in rural areas. ${ }^{8}$

Not all rural residents whose incomes fall below the poverty level rely on food stamps to help purchase food. In 2001, 10.6 million rural residents were poor, but only 4.6 million received food stamps. This suggests that many people who are likely to be eligible for help are not benefiting from the program. It is also possible, however, that individuals who anticipate only a short period of financial hardship may not apply for program assistance. ${ }^{9}$

\section{Rural Food Stamp Recipients: Children, Working Poor, Elderly and the Disabled}

In a snapshot of all rural residents relying on food stamps, almost half of the people in the picture are children. In 2001, while children accounted for only one-fourth of the rural population, they made up 43 percent of the rural population that depend on food stamps. Forty-nine percent of rural food stamp recipients were adults age 18 to 59 , while 8 percent were 60 and older.

In small town America, work often does not pay enough to make ends meet. Among rural adults age 18 to 59 who received food stamps, nearly four in ten were employed in 2001. For these rural residents, low wages and limited hours did not generate enough income to buy food. Thirteen percent of rural food stamp re-

8 McConnell, Sheena and James Ohls. 2000. "Food Stamps in Rural America: Special Issues and Common Themes." Paper presented at the Rural Dimensions of Welfare Reform: A Research Conference on Poverty, Welfare, and Food Assistance. Joint Center for Poverty Research, Northwestern University/University of Chicago.

9 Research finds many relatively short food stamp eligibility spells that do not result in program participation, and then end with increases in income. See, Blank, Rebecca and Patricia Ruggles. 1996. "When do Women Use Aid to Families with Dependent Children and Food Stamps? The Dynamics of Eligibility Versus Participation." Journal of Human Resources, Vol. 31, 1, 57-89. 
Distribution of rural food stamp recipients by age, 2001

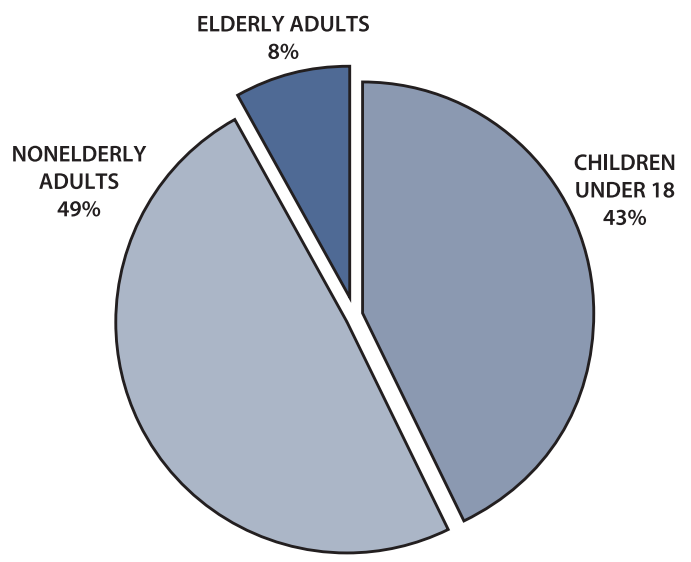

Source: 2001 SIPP Panel, Wave 1 Core Data

cipients were looking for work, and the remaining 48 percent were not in the labor force.

The Food Stamp Program plays an important role for rural residents who are living with disabilities as well. In 2001, 38 percent of rural recipients age 18 to 59 reported having a disability that limited the amount or type of work they could do.

As a group, rural elderly residents who receive food stamps are particularly disadvantaged. They have few resources and food stamps provide assistance in attaining a nutritious diet. In 2001, 91 percent of rural elderly in the Food Stamp Program had incomes less than 150 percent of the poverty level, and a similar proportion had no more than a high school education. Over three-fourths are single, many are widowed, and over two-thirds are women. A disproportionate share of these older, rural Americans receiving food stamps-72 percent-live in the South.

\section{Rural and Urban Food Stamp Beneficiaries: Race, Ethnicity, and Family Structure}

Rural and urban food stamp recipients share several characteristics. They are both more likely than the rest of the population to be children and living in singleparent households. Both rural and urban adults who benefit from the program are more likely than others to be disabled and less educated.

Yet, significant differences between rural and urban program beneficiaries exist, differences that tend to reflect overall differences between the nation's rural and urban populations. Rural residents who receive food stamps are more likely than their urban counterparts to be White, non-Hispanics. Fifty-three percent of rural food stamp recipients are White, compared with 34 percent of urban recipients. African-Americans and Hispanics make up 40 percent of recipients in rural areas, but 62 percent in urban areas. These differences are even more pronounced among adults age 60 and over. Two-thirds of rural food stamp recipients 60 years or older are White, non-Hispanic, compared with under one-half in urban areas.

Secondly, rural adult food stamp participants are more likely to be married than their urban counterparts. About 32 percent of adult food stamp recipients in rural areas are married, compared with 26 percent of urban food stamp recipients. Rural adults receiving food stamps are less likely to be never married than their urban counterparts (34 percent and 44 percent, respectively). Among those with children, a greater proportion of rural adult food stamp recipients are married (41 percent compared with 34 percent among urban recipients).

Food Stamp Recipients, by Race and Ethnicity, 2001

\begin{tabular}{|c|c|c|c|c|}
\hline \multirow[b]{2}{*}{ RACE \& ETHNICITY, (numbers in thousands) } & \multicolumn{2}{|c|}{ RURAL RESIDENTS } & \multicolumn{2}{|c|}{ URBAN RESIDENTS } \\
\hline & NUMBER & PERCENT & NUMBER & PERCENT \\
\hline White, non-Hispanic & 2,458 & 53.4 & 3,488 & 33.5 \\
\hline Black, non-Hispanic & 1,255 & 27.3 & 3,629 & 34.8 \\
\hline Hispanic & 575 & 12.5 & 2,850 & 27.4 \\
\hline Other, non-Hispanic & 313 & 6.8 & 454 & 4.4 \\
\hline
\end{tabular}




\section{A UNIVERSITY \\ - of NEW HAMPSHIRE}

\section{CARSEY \\ I N S T I T U T E}

Building knowledge to support rural communities in the 21ST Century.

The Carsey Institute at the University of New Hampshire is committed to building knowledge to meet the complex challenges confronting rural America. The Institute conducts non-partisan, interdisciplinary research and communicates its findings to policymakers, practitioners and the general public.

Huddleston Hall

Main Street

Durham, NH 03824

www.carseyinstitute.unh.edu

(603) 862-2821

The Carsey Institute Reports on Rural Families and Communities are supported by the Annie E. Casey Foundation's initiative to strengthen rural families and by the W.K. Kellogg Foundation.
Food stamps help out where needs in rural areas are the greatest. Thus, it is not surprising that rural beneficiaries are heavily concentrated in the South where rural poverty rates are significantly higher than elsewhere in the nation. Roughly three out of five rural residents who receive food stamps live in the South, although that region accounts for only 47 percent of the nation's rural population. Only 4 percent of rural

Percent of food stamp recipients by residence, 2001

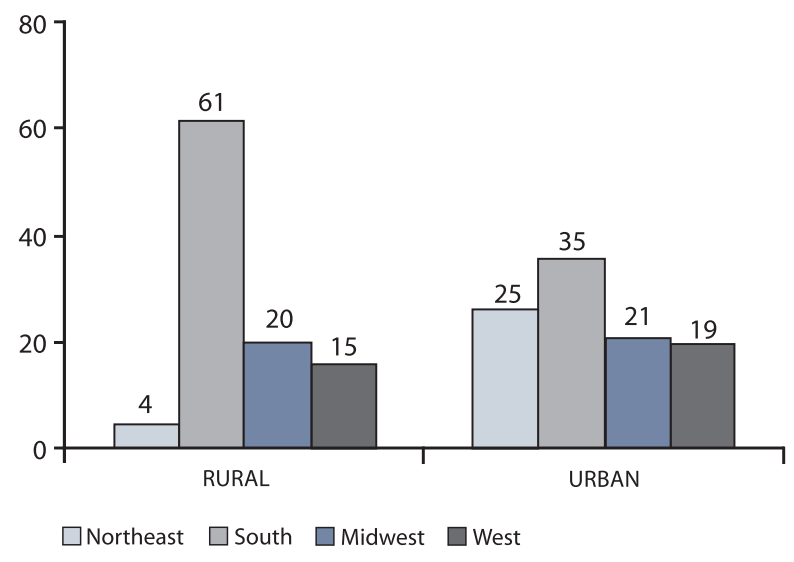

Source: 2001 SIPP, Wave 1 Core Data food stamp recipients live in the Northeast. No such striking regional concentration is evident among urban food stamp recipients.

\section{Conclusion: Protecting the Food Stamp Program}

The Food Stamp Program is a vital part of the safety net in rural America, helping a large number of children, disabled and elderly persons-particularly vulnerable and needy populations. In a time of rising housing costs, increasing poverty and a rising gap between the rich and the poor, Congressional decisions to cut the Food Stamp Program are likely to have significant adverse effects on the lives of poor rural Americans.

\section{Authors}

Kristin Smith, Family Demographer, Carsey Institute, Kristin.smith@unh.edu

Priscilla Salant, Associate Director, Carsey Institute, Priscilla.salant@unh.edu 